\title{
Three-Dimensional Trends Superposition in Digital Innovation Life Cycle Model
}

\author{
Vladimir F. Minakov ${ }^{1 *}$, Oleg S. Lobanov ${ }^{1}$, Sergey A. Dyatlov ${ }^{1}$ \\ ${ }^{1}$ St. Petersburg State University of Economics, 21, Sadovaya Street, 191023 St. Petersburg, Russian \\ Federation
}

\begin{abstract}
The concept of innovative products' life cycle as a superposition of growing interest in their consumption, as well as processes of falling demand, is substantiated in this study. This study found that such trends in the life cycle of innovations are unified. The development of the economic and mathematical model is based on the method of these trends' superposition. The result of this superposition is the unity of the mathematical representation of simultaneously occurring processes in the rise in demand for innovative products, consumer disappointment or crowding out by competitive innovative solutions. The mathematical description of each process is an original mathematical form that reflects the diffusion phenomena, which differs in the expression of the mathematical model parameters in the indicators form of real-time series of innovative products consumption. The principle of superposition and the unity of trends in the growth and decline of consumer interest in innovative products makes it possible to proactively establish the formation towards changing trends in the dynamics of innovative product consumption. These distinctive features of the model ensure transition from a qualitative to a quantitative representation of the Gartner cycle. This allows the use of the developed model to solve the problems of forecasting the consumption of innovations. In the growth phase, the processes of transition to the plateau of innovation success, the reversal of the growth trend and the onset of recession were identified. In the phase of movement to recession of the hype, the model makes it possible to predict the time of transition to an increase in consumption and to a plateau of innovation success. A special case of the proposed model is the cycle curve developed by Gartner in a descriptive form. The mathematical representation of such a case expands the applicability of the model to quantitative indicators of innovation processes.
\end{abstract}

Keywords: Change management; Cycles; Digital economy; Economic and mathematical model; Innovation management

\section{Introduction}

Market introduction, modernization and the disposal of modern innovative technologies and products have acquired distinctive features over the past decade. Indeed, in the global economy, the production of goods and services exceeds consumer demand (Glinskiy et al., 2018a). As a result, traditional products, especially during periods of crisis process manifestation (global in 2008-2009, as well as 2020), are significantly inferior in terms of demand and consumption as compared to innovative ones (Borisov and Pochukaeva, 2017).

*Corresponding author's email: thelobanoff@gmail.com, Tel.: +7-812-710-56-44 doi: $10.14716 /$ ijtech.v11i6.4444 
The manifestation of these processes is especially noticeable in the automotive market (Borisov and Pochukaeva, 2019) (suffice it to recall the filing of a bankruptcy petition for the world capital of the automotive industry of Detroit in 2013). In addition, there are problems of effective management of innovation and investment processes (Sklyarova et al., 2019). The changeable stages of success and problems in Elon Musk's companies are indicative.

Consequently, there is a need for the evolution of modeling methods in innovation management (Minakov et al., 2017; Glinskiy et al., 2018b). Indeed, Rogers' models and similar ones (Rogers, 2004; Rogers, 2015) reflected only the main processes and phases of the life cycle (the spread of innovations among "innovators, early adopters, early majority, late majority, lagging behind"). The lack of such models led to the formalization of local processes (including short-term) declines in interest in innovation (Rivera et al., 2006), followed by a partial or complete restoration of their spread (1995, model of hype cycles proposed by Gartner).

It is also important to note that the role of innovation has grown significantly in connection with the digitalization of the economy (Barykin et al., 2020). First, solutions in the field of information technology (IT solutions) have gone beyond the framework of auxiliary tools used by the personnel of enterprises to improve the efficiency of their activities (Karlik et al., 2019). They have long and successfully performed the functions of automation and control systems. ERP systems have expanded the boundaries of the use of information and communication systems and technologies (ICT) to business processes that go beyond enterprises - manufacturers of goods and services (Silkina et al., 2019). A large cluster of smart solutions has separated employees from functional processes implemented by automated IT solutions with elements of artificial intelligence. In addition, intelligent systems and technologies have put individuals in a position of dependence on capabilities and, for example, "smart proposals" of information systems based on intellectual analysis of data on the needs and preferences of a person based on his digital prints and traces (Ignatiev et al., 2019; Karlik et al., 2020).

Digital resources have played a significant role in the global economy during the COVID-19 pandemic. They have shown substitute properties in relation to traditional production factors. The most ambitious innovative role of ICT manifested itself as infrastructure (Dyatlov et al., 2018; Glinskiy et al., 2020), when its previous form did not meet the requirements of limiting physical interaction in the population to prevent the spread of coronavirus.

At the same time, to date, no economic and mathematical model has been created for detailing the life cycle of digital innovations, which would include a cycle of excitement. In this regard, the scientific task of verifying such a model is relevant. Based on this, the aim of this study is to develop economic and mathematical models of the innovation diffusion dynamics by phases of declining demand. In this regard, tasks of analyzing economic and mathematical models of innovative changes life cycle that have been completed to date should be solved, as well as the development of an approach to verify such models in the phase of decline in the innovation diffusion rate.

\section{Methods}

The new dynamics of the spread of innovative solutions is explained by the influence of information used by a person in the decision-making process as well as the digital systems used in the implementation of these decisions (Suryanegara et al., 2019). In technological structures based only on such factors of production as labor, land, capital, entrepreneurial abilities, the economic and mathematical model of volume of goods and services produced and in national economies, the gross domestic product has the form of a production function: 


$$
V(t)=K^{\alpha} \cdot L^{\beta} \cdot e^{\gamma \cdot t}
$$

where $K$ and $L$ are capital and labor used in production, $\alpha, \beta$ is the elasticity of manufactured products in terms of capital and labor, respectively. $\gamma$ is the indicator of scientific and technological progress rate and $e$ is the natural logarithm base.

However, such a model does not reflect the production decline processes in cases where all the resources included in the model are used in production processes, but the products turned out to be uncompetitive or unclaimed by the market. As a result, businesses may go bankrupt. On the other hand, those credit institutions that actively switched to online services and innovative products during that crisis period not only increased their client base but also successfully conducted an IPO, increasing their profits and their capitalization (Ivanter et al., 2016). The changes that took place were structural in nature and, as a result, the incomes of the raw materials sectors of the economy decreased significantly. This is illustrated by the dynamics of the price situation for the most important resource for real sectors of the economy (oil), as shown in Figure 1 (according to stock quotes https://ru.investing.com/).

Structural changes in the economy are reflected by the dynamics of the most important stock market indices, as shown in Figure 2 (Dow Jones) and Figure 3 (S\&P 500) (according to stock quotes https://ru.investing.com/).

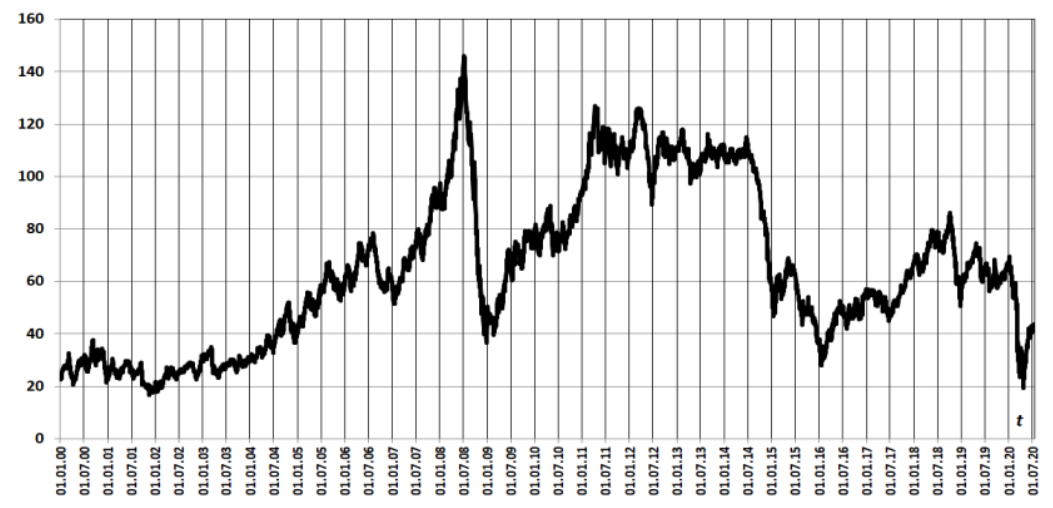

Figure 1 Dynamics of Brent crude oil quotes (USD per barrel)

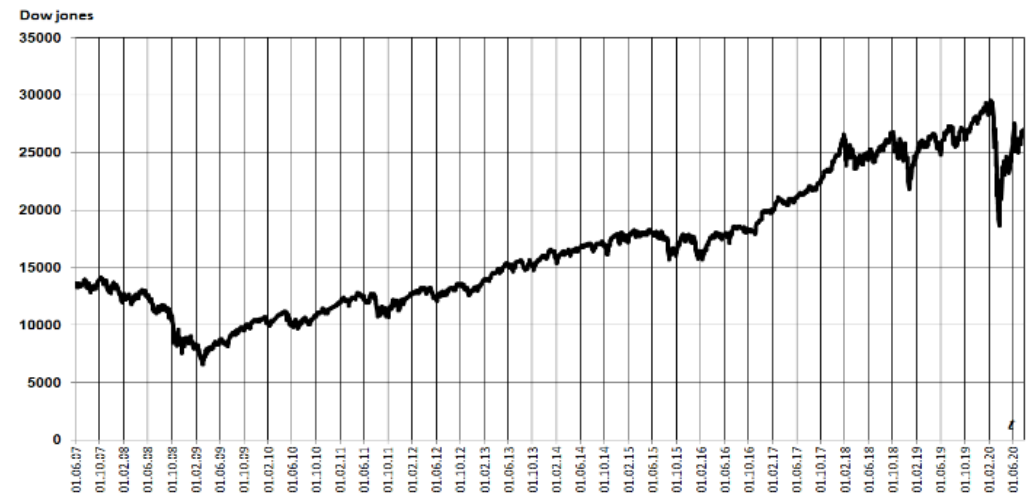

Figure 2 Dynamics of the Dow Jones index

Following the data in Figure 2, the Dow Jones index fell to 6547 in March 2009 (and to 18591 in March 2020), while in October 2007 it exceeded 14000 (and in February 2020, 29500). This influenced the capitalization of companies and, consequently, their ability to 
invest in production and innovation (Candra et al., 2020). Moreover, the state of capitalization of enterprises in the real sector of the economies of leading countries and, first of all, the United States, spread the problem to other countries, which ultimately led to the global economic crisis of 2008-2009.

The decrease in the S\&P 500 index from 1562 in October 2007 to 676 in March 2009 indicates that even the most large-scale industries made managerial decisions in a way that was not identical to the situation.

In the digital economy, the situation is complicated by uncontrolled processes with digital assets, especially those that are anonymous (Silkina et al., 2019), like bitcoin (Figure 4) (according to stock quotes https://ru.investing.com/).

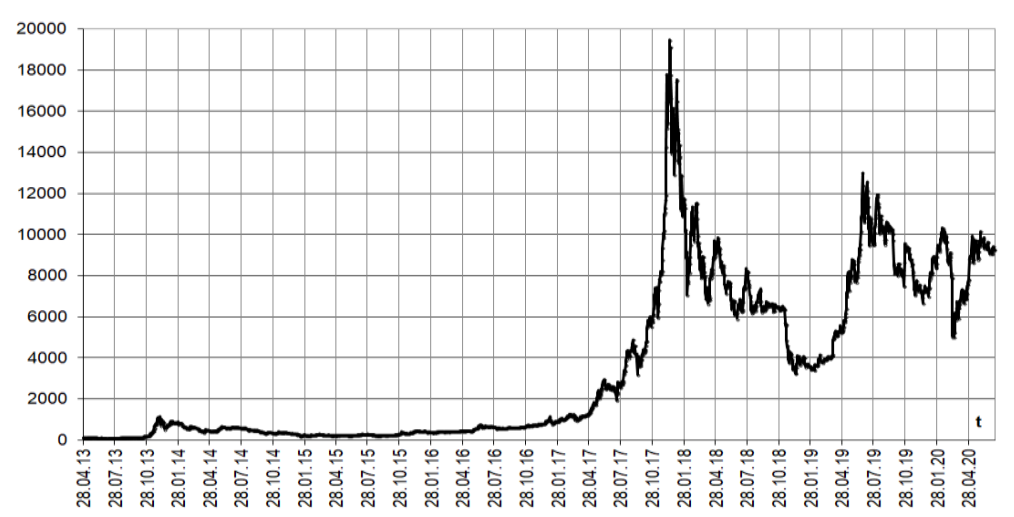

Figure 3 Dynamics of the S\&P 500 index

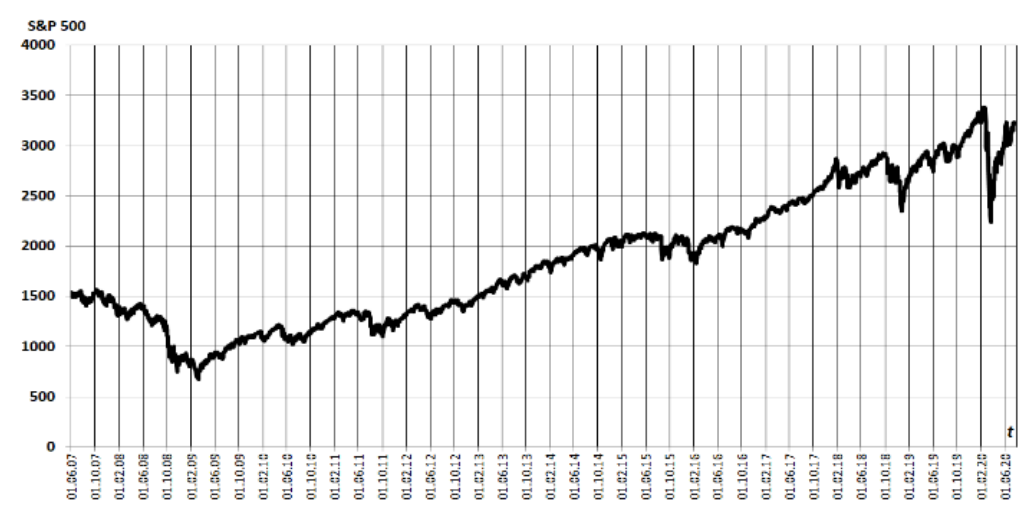

Figure 4 Bitcoin exchange rate dynamics, USD per 1 BTC

Figure 4 shows that digital assets can cause volatility that exceeds a normal level of volatility for tangible financial assets. It is obvious that price volatility is a manifestation of a more general pattern in the permanence of changes. First, they are caused by scientific and technological progress and, accordingly, innovations brought to markets (Yusuf et al., 2018). Revolutionary innovations and industrial revolutions led to the formation of new technological orders (from Industry 1.0 to the modern structure of Industry 4.0). Second, the competition between product manufacturers inevitably leads to price volatility. Third, spontaneous natural, epidemiological force majeure circumstances occur, leading to irreversible changes. All these changes are descriptively reflected in hype cycles (Gartner). For the mathematical modeling of the agiotage cycles, we used the regularities of diffusion processes expressing monotonic trends (Minakov et al., 2016).

The patterns of innovation diffusion were established and formalized in the diffusion model by (Rogers, 1962). First, according to this model, previous consumers of innovative 
products influence followers in proportion to their number. Second, the rate of diffusion of innovations decreases with the spread of innovations and is proportional to the remaining volume of the potential market segment. The mathematical model in the simplest case is the diffusion equation:

$$
d V^{*}(t) / d t=V^{*}(t) \cdot\left(1-V^{*}(t)\right)
$$

where $V^{*}(t)$ is the relative (reduced to the maximum value) variable value, for example, the final volume $V_{m}$ to which the use of an innovative product seeks:

$$
V^{*}(t)=V(t) / V_{m}
$$

To obtain a universal form of writing equations that are invariant to specific types of innovative products, relative values $V^{*}(t)$ are used. In this case, the transition to each case is performed by scaling, which results from (Equation 3):

$$
V(t)=V^{*}(t) \cdot V_{m}
$$

The solution to this diffusion equation is the logistic function (otherwise, the sigmoid):

$$
V^{*}(t)=1 /\left(1+e^{-t}\right)
$$

This function adequately reflects the trend of innovative changes; however, the origin and rate of trend formation do not allow the use of real-time units and sigmoid displacement in time. Moreover, the exponent of an exponential function cannot have the dimension of time (it must be dimensionless). Consequently, a sigmoid of the simplest type, strictly speaking, is not applicable for the time series modelling of innovation processes.

In this regard, the theory of innovation management uses modified diffusion equations and their solutions. The most widespread was the Bass model (Bass, 1969; Jiang et al., 2006):

$$
d V^{*}(t) / d t=\left(p+q \cdot V^{*}(t)\right) \cdot\left(1-V^{*}(t)\right)
$$

where $q$ is the consumer-innovator influence coefficient and $p$ is the consumer-imitator influence coefficient.

The Bass model and the solution to its diffusion equation have a higher accuracy; however, its parameters are devoid of economic sense and, therefore, cannot be directly used in innovation processes management.

The success of using mathematical models of diffusion type motivated the use of a wide range of such equations. This is a logistic model (or logistic equation), which is characterized by the introduction of a scale factor $q$, which makes it possible to consider the difference (with a multiplicity of $q$ ) in the rates of innovation diffusion (Mahajan and Peterson, 1985):

$$
d V^{*}(t) / d t=q \cdot V^{*}(t) \cdot\left(1-V^{*}(t)\right)
$$

In some cases, there is a quadratic slowdown in the rate of innovation diffusion in accordance with the Floyd model (Floyd, 1962):

$$
d V^{*}(t) / d t=q \cdot V^{*}(t) \cdot\left(1-V^{*}(t)\right)^{2}
$$

The general case of the exponential law of deceleration is described by the model (Sharif and Kabir, 1976):

$$
d V^{*}(t) / d t=q \cdot V^{*}(t) \cdot\left(1-V^{*}(t)\right)^{z}
$$


where $z$ is the rate of deceleration.

To account for the heterogeneity of deceleration rate in the diffusion of the innovations, the mathematical function of Gompertz is often used (Gompertz, 1825):

$$
V^{*}(t)=a \cdot e^{b \cdot e^{c \cdot t}}
$$

where $a, b$ and $c$ are the coefficients that change the bias and the rate of function change.

In cases where it is required to consider a priori a given function of time $h(t)$, which affects the course of innovation process (for example, the amount of funding, control actions and the volume of sales), the Mansfield model is used (Mansfield, 1968):

$$
d V^{*}(t) / d t=h(t) \cdot\left(1-V^{*}(t)\right)
$$

The NSRT (Nonsymmetric Responding Logistic Model), in which the exponential nature of rate changes is due to the growth of $d V^{*}(t)$, is among the models that reproduce asymmetric phases of innovation diffusion (Easingwood et al., 1981):

$$
d V^{*}(t) / d t=q \cdot\left(V^{*}(t)\right)^{z} \cdot\left(1-V^{*}(t)\right)
$$

We also note that in attempts to improve the accuracy of innovation diffusion models, numerous simple additions to logistic equations with additional functions are proposed, each of which considers additional factors that influence innovation processes (Dixon, 1980; Bewley and Flebig, 1988). However, they do not change the basic approach to modelling innovation diffusion, which consists of reproducing the exclusively growing nature of innovation diffusion. At the same time, as practice shows (Minakov et al., 2016) is a characteristic of many innovative processes, the dynamics of distribution indicators often have recessions with resumption of recovery phases, which require the development of diffusion models.

We propose a modification of the diffusion equation. Usually it is based on usage abstract coefficients as parameters that indirectly reflect the rate of diffusion of innovations. But we base our model on real measured quantities, in particular, new variable that is time constant (T) (Minakov et al., 2015) in the form:

$$
d V^{*}(t) / d t=V^{*}(t) \cdot\left(1-V^{*}(t)\right) / T
$$

Its solution is quite simple:

$$
V_{n}^{*}(t)=1 /\left(1+e^{\left(t-t_{o}\right) / T}\right)
$$

where $t_{o}$ is the constant of integration, numerically equal to the physical mixing time of the sigmoid of the simplest form relative to origin (modelling), and $T$ is the time constant of exponential asymptotic approximation of process indicator $V^{*}(t)$ to the asymptote that is numerically equal to one.

The above usage for the variability of economic conditions, which characterize the regularity of growth and decline, should be expressed in a mathematical model. To do this, a mathematical diffusion model is being developed with recession phases along with growth phases. This model is based on the proposal of Minakov et al. (2017)'s conceptual provisions on the representation of innovation processes dynamics by superposition (difference) of sigmoids, reflecting the processes of growth and decline.

After the rush demand reaches its maximum value, the time interval for a decrease in demand begins. For the proposed modification of the diffusion equation and its solution as a new component (a falling sigmoid), its mathematical model can be presented as: 


$$
V_{-}^{*}(t)=1-1 /\left(1+e^{\left(t-t_{-}\right) / T_{-}}\right)
$$

Now we shall present a new model of changes (for example, the diffusion of innovations) in a generalized form based on the superposition of agiotage processes of growth and decline in innovative product consumption. The model is:

$$
V^{*}(t)=\sum_{i=1}^{I}\left[1 /\left(1+e^{-\left(t-t_{o, i}\right) / T_{o, i}}\right)-k_{i} /\left(1+e^{-\left(t-t_{-, i}\right) / T_{-, i}}\right)\right]
$$

where $k_{i}$ is the share effect of recession in relation to the rise in demand for an innovative product and $i$ is the number of phases of cyclical dynamics of demand for innovation.

The first case of the proposed model is the innovation life cycle. Indeed, the spread of an innovative solution are sigmoids of growth trends $1 /\left(1+e^{-\left(t-t_{o, i}\right) / T_{o, i}}\right)$, and recessions are sigmoids of declining demand and consumption trends $-k_{i} /\left(1+e^{-\left(t-t_{-, i}\right) / T_{-, i}}\right)$

Another special case of the generalized model is the Gartner hype cycle:

$$
V_{n}^{*}(t)=1 /\left(1+e^{-\left(t-t_{m}\right) / T_{m}}\right)-k /\left(1+e^{-\left(t-t_{n}\right) / T_{n}}\right)
$$

The simulation result obtained based on the proposed mathematical model is fully consistent with Gartner's cycle, reflecting its key phases. It allows one to obtain several new results that numerically characterize the processes of diffusion of innovations, as well as cyclical processes of decreasing demand for them, sustainable consumption and subsequent disposal.

\section{Results and Discussion}

Based on the developed economic and mathematical model, we calculated the dynamic indicators of innovations spread $\mathrm{V}^{*}(\mathrm{t})$. To generalize the calculation results, we normalized the limit value by converting it to 100 units (for example, percent). Then, the diffusion of innovations $\mathrm{V}^{*}(\mathrm{t})$, obtained using the proposed mathematical model (Equation 17), considering the hype cycle, can be visualized in quantitative terms by the data shown in Figure 5.

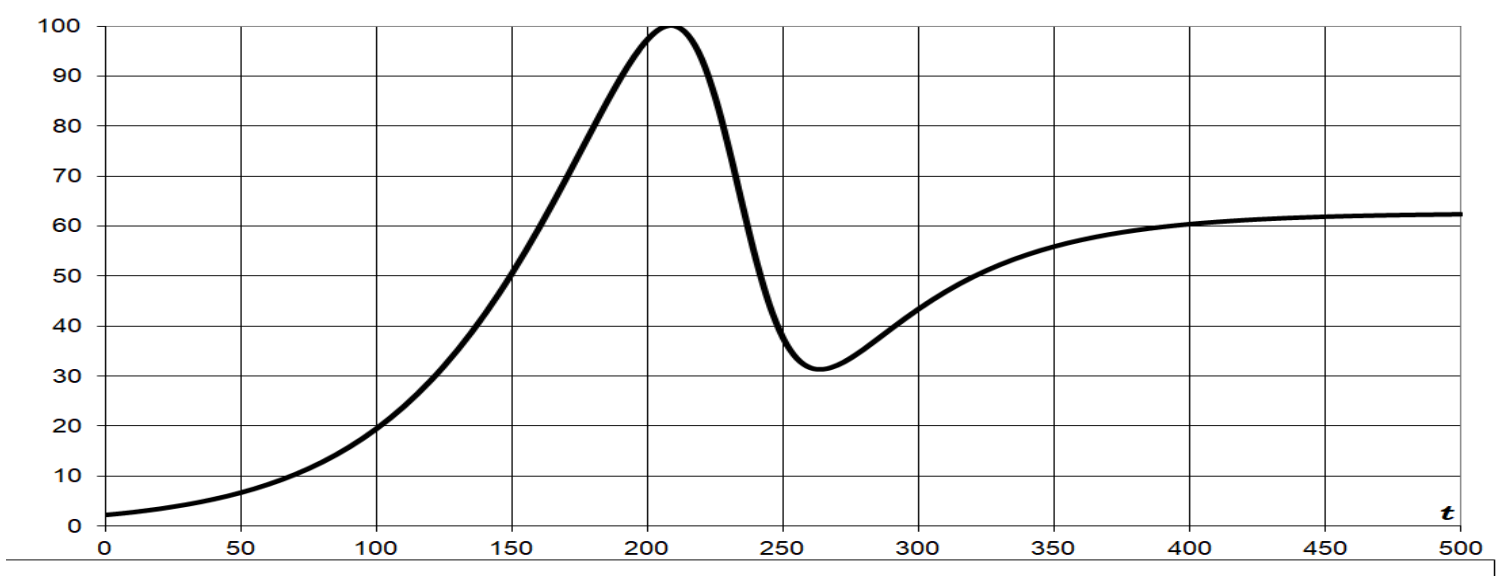

Figure 5 Results of modeling Gartner's innovation cycle 
Figure 5 shows that the developed model is adequate to temporal dynamics of innovation diffusion in accordance with the Gartner cycle, reflecting innovation launch (for example, technologies), excitement (for example, information hype, peak of overestimation of expectations), decline in demand, bottom of demand and consumption plateau. The simulation was performed using the following parameter values: $t_{o}=200 ; t_{-}=233 ; k=0.7 ; T$ $=44 ; T_{n}=11$. The analysis of the result obtained - an economic and mathematical model of the superposition of agiotage processes of growth and decline in demand for innovations is carried out by changing the parameter of the model $k$ in the 0.1 to 0.8 range. The results of the authors' calculations reflecting quantitative indicators of innovation spread (demand $V$ ) are shown in Fig. 6 . They allow us to establish that model parameter $k$ affects demand in the phases of demand decline, as well as the ratio of its level in the zone of demand bottom in relation to the peak of expectations.

An important property of the developed economic and mathematical model is the direct correspondence between the model parameters and the parameters of economic processes. Therefore, the identification of the named values by mathematical methods obtains real values, first, characterizing the cycle of excitement and, second, using them as metrics in the management of economic processes (for example, innovations) and measurements in real economic systems (for example, for monitoring). Therefore, the displacement of the sigmoid rise and fall is determined by the following model parameters:

$$
\Delta t=t_{m}-t_{n}
$$

We shall note that this indicator is important for practical use, since it reflects the regularity of the sigmoid formation of decline in interest in an innovative product and, therefore, is a tool for risk management of innovation. The values estimation allows using the resource of time to create conditions that ensure the dominance of the growth trend in consumption over the decline trend (for example, by informing consumers about the characteristics of innovative products through modern information and telecommunication networks and systems).

It is important to note that the decomposition of trends into upward and downward trends gives a much more complete picture of innovation diffusion dynamics. Thus, the traditional logistic function in modeling the time series of demand for innovation in the event of a slowdown in demand growth means reaching a plateau of stable demand and successful production and sales of products. However, a decrease in this rate can be caused by the formation of a downward trend in interest in innovation. And in the case of identifying this trend, it is possible to predict not the movement of the market towards stable demand but, on the contrary, a reversal of demand and a subsequent decline. In this case, decay sigmoid in decomposition trend is a strict criterion for deciding whether to make adequate management decisions. These can be marketing activities.

On the contrary, an absence of falling sigmoid makes it possible to decide on the concentration of production resources to increase the output of products, the demand for which is characterized by an upward trend. Consequently, the developed economic and mathematical model provides a new indicator that is leading and, therefore, effective for solving forecasting problems.

In the digital economy, information flows and the amount of information are effective tools in influencing consumer decision-making. They shape consumers' understanding of the value of innovative products as well as how they can be effectively used, etc. Such flows have acquired exceptional importance in the context of isolation and restrictions imposed by developed and developing economies to prevent the spread of the coronavirus. 


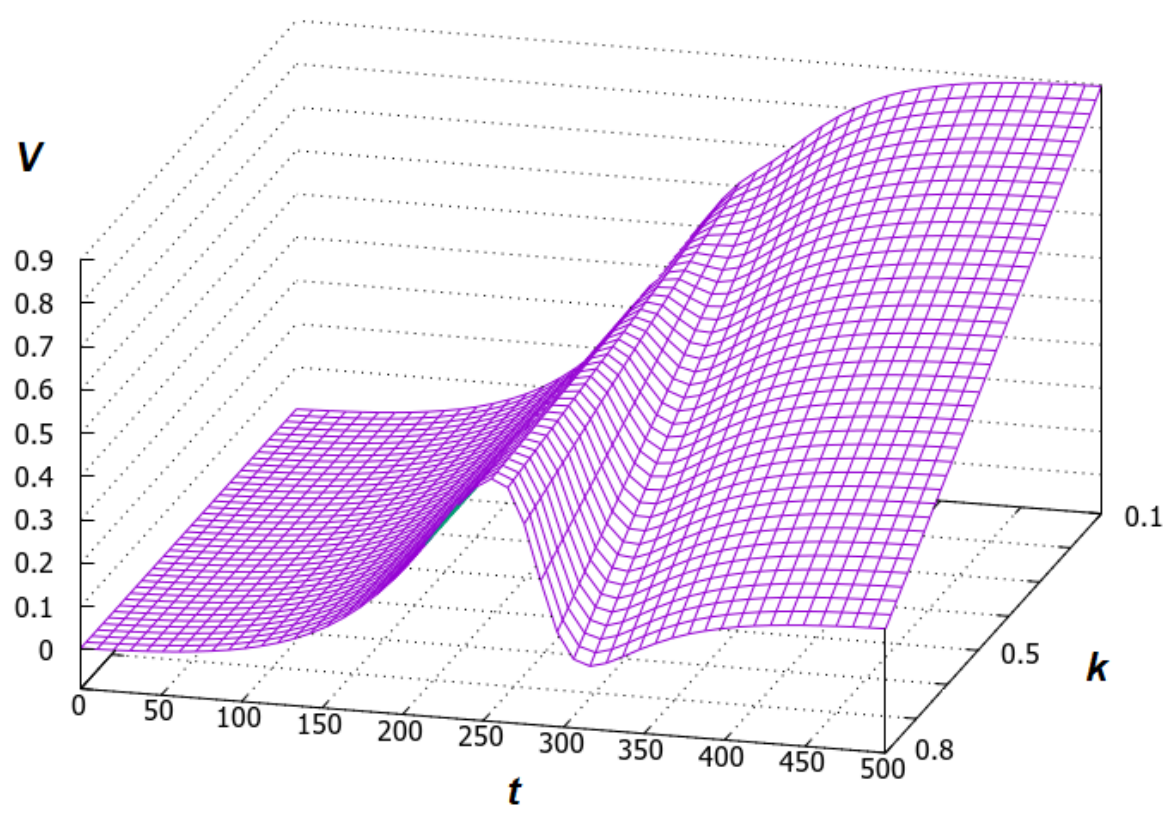

Figure 6 Impact of counteraction factors on the Gartner cycle

During these times, the dominant means of communication are computer networks and services for teleworking, receiving orders, delivery and payment are all done online. It is in the information space and online that consumers make the greatest number of decisions on purchasing goods at this time. Obviously, under current conditions, information increases its influence on alternative generation, understanding, choice, and formation of material and financial flows in the digital economy, which becomes a reality in post-COVID times.

\section{Conclusions}

The concept of innovation processes represented as a superposition of diffusion trends made it possible to verify the economic and mathematical models of innovation diffusion, which is distinguished through an adequate mathematical description of the complete life cycle of innovation. In this case, a special model is the model of agiotage cycles proposed by Gartner. In this model, manifestation and diffusion result in the processes of rush demand. An increase in consumption due to an increased consumer value of innovative products compared to existing and traditional products and a decrease in demand due to the formation of opposing factors. These opposing factors include a lack of financial resources and an avalanche effect on the company, which includes manufacturing of innovative products, risks arising from the use of innovation by consumers (for example, information, in information and communication systems), the influence of competitive environment, the development of alternative innovative solutions and many others. In the economic and mathematical model developed, the superposition of growth and decline processes in the consumption of innovative products not only increases the accuracy of modelling innovative processes but also obtains new predictive indicators (leading indicators). Therefore, by identifying the parameters of this model, the presence or absence of a decline trend and, consequently, the subsequent breakdown of the general trend in innovative products sales dynamics are identified. The authors carried out modelling and obtained quantitative results for the rush cycle of innovations spread for the following parameters: $t_{o}=200 ; t_{-}=233 ; k=0.7 ; T=44 ; T_{n}=11$. In addition, a calculation was performed and a three-dimensional representation of demand indicators for innovative 
products was obtained when the ratio of the growth parameters of demand diffusion and its inhibition ( $k$ in the range from 0.1 to 0.8 ) were changed. The results obtained (demand level $V$ in three-dimensional representation are the basis of managerial decisions in innovation management systems, which include activating advertising, increasing production volumes, attracting and distributing financial, labor and other resources (or vice versa) and modernizing or disposing outgoing innovative solutions. Thus, the developed model, as well as new indicators of innovation processes obtained on its basis, will increase the efficiency of digital innovation management invariant to the type of digital innovative product.

\section{References}

Barykin, S., Gazul, S., Kiyaev, V., Kalinina, O., Yadykin, V., 2020. Forming Ontologies and Dynamically Configurable Infrastructures at the Stage of Transition to Digital Economy Based on Logistics. Advances in Intelligent Systems and Computing. Volume 1116 AISC, pp. 844-852

Bass, F., 1969. A New Product Growth Model for Consumer Durables. Management Science, Volume 15(5), pp. 215-227

Bewley, R., Fiebig, D., 1988. Flexible Logistic Growth Model with Applications in Teleconmunication. International Journal of Forecasting, Volume 4(2), pp. 177-192

Borisov, V.N., Pochukaeva, O.V., 2017. Investment and Innovative Technological Efficiency: Case Study of the Arctic Project. Studies on Russian Economic Development, Volume 28(2), pp. 169-179

Borisov, V.N., Pochukaeva, O.V., 2019. Investment Activity and Investment Efficiency in the Mechanical Engineering Industry. Studies on Russian Economic Development, Volume 30(5), pp. 547-556

Candra, S., Nuruttarwiyah, F., Hapsari, I.H., 2020. Revisited the Technology Acceptance Model with E-Trust for Peer-to-Peer Lending in Indonesia (Perspective from Fintech Users). International Journal of Technology, Volume 11(4), pp. 710-721

Dixon, R., 1980. Hybrid Corn Revisited. The Econometric Society, Volume 48(6), pp. 14511461

Dyatlov, S.A., Lobanov, O.S., Zhou, W.B., 2018. The Management of Regional Information Space in the Conditions of Digital Economy. Economy of Region, Volume 14(4), pp. 1194-1206

Easingwood, C., Mahajan, V., Muller E.A., 1981. Nonsymmetric Responding Logistic Model for Forecasting Technological Substitution. Technological Forecasting and Social Change, Volume 20(3), pp. 199-213

Floyd, A., 1962. Trend Forecasting: A Methodology for Figure of Merit. In: Technological Forecasting for Industry and Government: Methods and Applications, J. Bright (ed.), Technological Forecasting for Industry and Government. New Jersey Prentice Hall, New Jersey, USA, pp. 95-105

Glinskiy, V., Serga, L., Alekseev, M., Samotoy, N., Simonova, E., 2018a. The Development of the Food Industry as a Condition for Improving Russia's National Security. Procedia Manufacturing, Volume 21, pp. 838-845

Glinskiy, V., Serga, L., Khvan, M., Zaykov, K., 2018b. The Assessment Methods of the Level of Countries Environmental Safety. Procedia Manufacturing, Volume 21, pp. 494-501

Glinskiy, V.V., Serga, L.K., Alekseev, M.A., 2020. Territorial Differentiation as the Factor of Sustainable Economic Development. Procedia Manufacturing, Volume 43, pp. 263-268

Gompertz, B., 1825. On the Nature of the Function Expressive of the Law of Human Mortality, and on a New Mode of Determining the Value of Life Contingencies. 
Philosophical Transactions of the Royal Society of London, Volume 115(1825), pp. 513583

Ignatiev, M.B., Karlik, A.E., Iakovleva, E.A., Platonov, V.V., 2019. Linguo-Combinatorial Model for Diagnosing the State of Human Resources in the Digital Economy. In: Proceedings of the $17^{\text {th }}$ Russian Scientific and Practical Conference on Planning and Teaching Engineering Staff for the Industrial and Economic Complex of the Region, PTES 2018. 8604217, pp. 201-204

Ivanter, V.V., Belkina, T.D., Belousov, D.R., Yankov, K.V., Zaionchkovskaya, Z.A., 2016. Recovery of Economic Growth in Russia. Studies on Russian Economic Development, Volume 27(5), pp. 485-494

Jiang, Z., Bass, F.M., Bass, P.I., 2006. Virtual Bass Model and the Left-Hand Data-Truncation Bias in Diffusion of Innovation Studies. International Journal of Research in Marketing, Volume 23(1), pp. 93-106

Karlik, A.E., Platonov, V.V., Yakovleva, E.A., 2019. System Analysis of the Implementation of the Virtual Forms Human-computer Interaction in the Higher Education Sector: Results of the Review of the Experience of Implementation of the Virtual Forms. In: Proceedings of the XI International Scientific Conference Communicative Strategies of the Information Society, pp. 1-6

Karlik, A.E., Platonov, V.V., Yakovleva, E.A., 2020. A Framework for the Analysis of ResourceFlows in the Extended Manufacturing Network based on Cyber-Physical Infrastructure. Lecture Notes in Networks and Systems, Volume 95, pp. 564-572

Mahajan, V., Peterson, R., 1985. Models for Innovation Diffusion (Quantitative Applications in the Social Sciences). Sage University Paper, Volume 48, pp. 1-88

Mansfield, E., 1968. The Economics of Technological Change. New York, W. W. Norton \& Company, Inc.

Minakov, V.F., Galstyan, A.S., Piterskaya, L.Y., Radchenko, M.V., Shiyanova, A.A., 2016. Innovative Investment Trends in the Northern Caucasus. Central Asia and the Caucasus, Volume 17, pp. 61-70

Minakov, V.F., Minakova, T.E., Galstyan, A.S., Shiyanova, A.A., 2015. Time Constant of Innovation Effects Doubling. Mediterranean Journal of Social Sciences, Volume 6(36), pp. 307-312

Minakov, V.F., Minakova, T.E., Lobanov, O.S., Kostin, V.N., Makarchuk, T.A., 2017. The Expansion of Time Series Innovations in a Series of Sigmoid. International Journal of Applied Business and Economic Research, Volume 15(18), pp. 311-319

Rivera, M.A., Rogers, E.M, 2006. Innovation Diffusion, Network Features, and Cultural Communication Variables. Problems and Perspectives in Management, Volume 4(2), pp. 126-135

Rogers, E., 1962. Diffusion of Innovations. New York: A Division of Macmillan Publishing Co./London: Collier Macmillan Canada, Inc.

Rogers, E.M, 2015. Evolution: Diffusion of Innovations. In: International Encyclopedia of the Social and Behavioral Sciences. $2^{\text {nd }}$ Edition, University of Central Florida, Orlando, FL, USA, pp. 378-381

Rogers, E.M., 2004. A Prospective and Retrospective Look at the Diffusion Model. Journal of Health Communication, Volume 9, pp. 13-19

Sharif, M.N., Kabir, C.A., 1976. Generalized Model for Forecasting Technological Substitution. Technological Forecasting and Social Change, Volume 8(4), pp. 353-364

Silkina, G., Barabanova, M., Gazul, S., Kiyaev, V., 2019. Using Blockchain-based Approach for Building the System Events Logging Service. In: Journal of Physics: Conference Series. 
International Scientific Conference "Conference on Applied Physics, Information Technologies and Engineering - APITECH-2019", pp. 33-75

Sklyarova, Y.M., Sklyarov, I.Y., Taranova, I.V., Latysheva, L.A., Piterskaya, L.Y., 2019. The Main Directions of Development the Banking and Financial Management System: Theory and Practice. Indo American Journal of Pharmaceutical Sciences, Volume 6(3), pp. $5615-5619$

Suryanegara, M., Harwahyu, R., Asvial, M., Setiawan, E.A., Kusrini, E., 2019. Information and Communications Technology (ICT) as the Engine of Innovation in the Co-Evolution Mechanism. International Journal of Technology, Volume 10(7), pp. 1260-1265

Yusuf, M.F., Ashari, H., Razalli, M.R., 2018. Environmental Technological Innovation and Its Contribution to Sustainable Development. International Journal of Technology, Volume 9(8), pp. 1569-1578 